\section{Inhibitory activity of stilbenes against filamentous fungi}

Luce Mattio, ${ }^{1}$ Giorgia Catinella, ${ }^{1}$

Marcello Iriti, ${ }^{2}$ Lisa Vallone ${ }^{3}$

${ }^{1}$ Department of Food, Environmental and Nutritional Sciences, University of Milan; ${ }^{2}$ Department of Agricultural and Environmental Sciences, University of Milan; ${ }^{3}$ Department of Health, Animal Science and Food Safety "Carlo Cantoni”, University of Milan (VESPA), Italy

\begin{abstract}
Stilbenoids (resveratrol and its derivatives) are secondary metabolites produced by plants as defence mechanism to microbial infection. These compounds are known for their anti-inflammatory action and health benefits in preventing a wide range of disorders (e.g. cancer and cardiovascular diseases). However, their antimicrobial properties are less investigated. A series of 8 stilbenoid compounds were synthesized and their antifungal activity against 19 wild strains of filamentous fungi and yeasts (isolated from the environment and food) was tested in vitro. Using an agar diffusion assay, compounds were tested at the concentration of $100 \mu \mathrm{g} / \mathrm{ml}$ on filamentous fungi and yeasts at $10^{4} \mathrm{CFU} / \mathrm{ml}$. The results showed that tested derivatives possess moderate antifungal activity: in particular, monomeric stilbenoids 3'-hydroxy-pterostilbene and piceatannol, and dimeric stilbenoids $( \pm)$-trans- $\delta$-viniferin and pallidol were active against mycotoxigenic fungi.
\end{abstract}

\section{Introduction}

Stilbenoids are among the most important classes of phytoalexins produced by 72 plant species belonging to 31 genera, with a particular emphasis on stilbenes from the Vitaceae (Valletta et al., 2021; Jaillon et al., 2007). Over 400 different stilbenoids are currently known (El Khawand et al., 2018), mostly derived from trans-resveratrol (3,5,4'-trihydroxy-trans-stilbene), although different structures can be found in some plant families (Chong et al., 2009).

Stilbenoids are mainly involved in constitutive and inducible protection of the plant against biotic (phytopathogenic microorganisms and herbivores) and abiotic (e.g. UV radiation and tropospheric ozone) stresses (Chong et al., 2009; Jeandet et al.,
2010), due to their antibiotic and antioxidant activities (Valletta et al., 2021). Among stilbenoids, resveratrol is the most investigated and its health benefits as anti-inflammatory, anticancer, estrogenic, neuroprotective, cardio protective, anti-atherosclerotic, anti-aging, anti-diabetic, anti-osteoporosis and anti-obesity agent have been documented in several preclinical (in vitro/in vivo) studies (Valletta et al., 2021).

In the last decades, the interest in resveratrol has been amplified since its presence in wine was indicated as a possible explanation for the "French paradox", i.e. the reduced risk of cardiovascular disease associated to moderate, regular consumption of red wine at main meals for people consuming a diet rich in saturated fats (Catalgol et al., 2012; Jeandet et al., 2021).

Currently, resveratrol has been exploited in pharmaceutical, cosmetic and food industries. In this latter area, possible applications as antimicrobial agent in the conservation of food are under evaluation ( $\mathrm{Oh}$ et al., 2018; Ma et al., 2018). The in vitro antimicrobial properties of resveratrol are widely known (Albert et al., 2011; Chalal et al., 2014), although the mechanism of action on pathogenic and food-borne bacteria, fungi and yeasts is not yet fully understood (Lee et al., 2015).

Resveratrol exhibited inhibitory activity against yeasts and filamentous fungi (Seppanen et al., 2019) such as Botrytis cinerea (Adrian et al., 1997; Hoss et al., 1990; Paul et al., 1998; Sarig et al., 1997), Rhizopus stolonifer (Valletta et al., 2021), Phomopsis viticola (Hoss et al., 1990), Fusarium nivale (Bala et al., 1999), Saccharomyces cerevisiae, Penicillium expansum and Aspergillus niger (Seppanen et al., 2019; Valletta et al., 2021; Adrian et al., 1997). Conversely, Weber et al. (Weber et al., 2011), showed that resveratrol was not active on several Candida species (Weber et al., 2011; Shevelev et al., 2018), though recent reports suggested that resveratrol derivatives could inhibit Candida species as well (Lee et al., 2015; Shevelev et al., 2020).

Recently, other monomeric and oligomeric stilbenoid derivatives including pterostilbene, pinosylvin, piceatannol and viniferins have attracted the attention of researchers. Pterostilbene and trans- $\varepsilon$ viniferin have been found to be 5-fold more active than resveratrol as antifungal agents, indicating their high antimicrobial potential (Chalal et al., 2014; Houillé et al., 2014). These compounds were tested in vitro against $B$. cinerea, and pterostilbene, in particular, inhibited conidial germination and in vitro mycelium growth more effectively than resveratrol, indicating that methylation
Correspondence: Lisa Vallone, Dipartimento VESPA, Via dell'Università n. 9, Lodi (LO), Italy.

Tel. +39.250334312.

E-mail: lisa.vallone@unimi.it

Key words: Stilbenes, Resveratrol, Antimicrobial activity, Food-borne fungi.

Acknowledgments: The work of Giorgia Catinella has been partially funded by Fondazione F. $11 \mathrm{i}$ Confalonieri (PhD Scholarship).

Contributions: The authors contributed equally.

Conflict of interest: The authors declared no potential conflict of interest.

Received for publication: 31 July 2020.

Revision received: 15 November 2020.

Accepted for publication: 18 November 2020

This work is licensed under a Creative Commons Attribution-NonCommercial 4.0 International License (CC BY-NC 4.0).

(C) Copyright: the Author(s), 2021

Licensee PAGEPress, Italy

Italian Journal of Food Safety 2021; 10:8461 doi:10.4081/ijfs.2021.8461

of -OH groups could have a role in the antifungal activity. Schouten et al. (Schouten et al., 2002) demonstrated that resveratrol, though not toxic to $B$. cinerea, is converted into a fungitoxic derivative by a specific fungal laccase (Caruso et al., 2011).

A possible mode of action of stilbenoids may involve membrane peroxidation (Lee et al., 2017). Pterostilbene caused destruction of the endoplasmic reticulum, and the nuclear and mitochondrial membranes in $B$. cinerea dormant conidia. A positive correlation between antifungal activity of natural and synthetic stilbenoids and their hydrophobicity was found, suggesting that pterostilbene is more active than the less hydrophobic resveratrol due to its increased diffusion through the cytoplasmic membrane (Caruso et al., 2011).

Owing to the need of alternative compounds to control food spoilage and contamination, the aim of this study was to assay in vitro the antimicrobial activity of a small collection of stilbenoid monomers and dimers against filamentous fungi and yeasts isolated from the environment and food of animal origin.

\section{Materials and methods}

Sixteen fungal strains, Alternaria alter- 
nata, Aspergillus flavus, Aspergillus niger, Aspergillus ochraceus, Aspergillus terreus, Byssochlamys nivea, Botrytis cinerea, Fusarium graminearum

Fusarium verticillioides, Geotrichum candidum, Mucor circinelloides, Penicillium expansum

Penicillium italicum, Penicillium roqueforti, Rhizopus nigricans and 3 yeast strains Candida albicans, Candida parapsilosis, Malassetia pachydermatis were grown to assess the inhibitory activity of 4 monomeric stilbenoids (i.e. resveratrol, piceatannol, pterostilbene, 3'-hydroxypterostilbene) and 4 dimers (i.e. $( \pm)$-trans- $\delta$ viniferin, $( \pm)$-trans- $\varepsilon$-viniferin, pallidol $( \pm)$ pterostilbene-trans-dihydrodimer) (Figure 1). Stilbenoids were dissolved in DMSO to obtain a stock solution of $10 \mathrm{mg} / \mathrm{ml}$. Wild strains were used instead of ATCC strain because more aggressive and less tamed to tested compounds.

The bioassay was carried out on Sabouraud agar medium, by paper disk diffusion assay. From microbanks, all the mycetes were first suspended into $\mathrm{M}_{2}$ broth and incubated for 5 days at $25^{\circ} \mathrm{C}$. A spectrophotometer was used to adjust the final cell concentration at $10^{4} \mathrm{cfu} / \mathrm{ml}$ by reading the $\mathrm{OD}$ at $600 \mathrm{~nm}$.

Then, $100 \mu 1$ of the microbial suspensions were spread on Sabouraud agar medium. The 6-mm-diameter, sterile disks impregnated with $10 \mu \mathrm{l}$ of stilbenoid compounds at the concentration of $100 \mu \mathrm{g} / \mathrm{ml}$ were placed on the inoculated agar. The inoculated plates were incubated at $25^{\circ} \mathrm{C}$ for 7 days. As positive controls, cyclopiroxolamine and tebuconazole $(1 \mu \mathrm{g} /$ disk $)$ were used. Inhibitory activity was determined by measuring the zone of inhibition.

\section{Results}

The inhibitory activity of the tested stilbenoids varied according to the different strains. Piceatannol showed an antifungal activity against $P$. roqueforti, A. flavus, $P$. italicum, A. terreus, $G$. candidum, $F$. verticillioides and $C$. parapsilosis. 3'-Hydroxypterostilbene affected the growth of $C$. parapsilosis, $P$. roqueforti, $A$. ochraceus, $A$. flavus and $C$. albicans. Pallidol inhibited the growth of $P$. italicum and $F$. verticil- lioide. Finally, $( \pm)$-trans- $\delta$-viniferin and $( \pm)$ pterostilbene-trans-dihydrodimer were effective only on one strain, $A$. flavus and $F$. verticillioides, respectively. Overall, $A$. flavus was sensitive to piceatannol, $\delta$ viniferin and 3'-hydroxy-pterostilbene; $F$. verticillioides was sensitive to $( \pm)$-pterostilbene-trans-dihydrodimer, pallidol and piceatannol; P. roqueforti was sensitive to piceatannol and 3'-hydroxy-pterostilbene; $P$. italicum was sensitive to pallidol and piceatannol and $C$. parapsilosis was sensitive to 3'-hydroxy-pterostilbene and piceatannol; A. terreus and $G$. candidum were sensitive to piceatannol; $A$. ochraceus and $C$. albicans were sensitive to 3'hydroxy-pterostilbene (Table 1). Values are mean inhibition zone $(\mathrm{mm}) \pm$ S.D. of three replicates; positive controls (tebuconazole and cyclopiroxolamine) $>20 \mathrm{~mm}$.

\section{Discussion}

Results indicated that the antifungal activity of selected stilbenoids was strictly related to the chemical structure of the

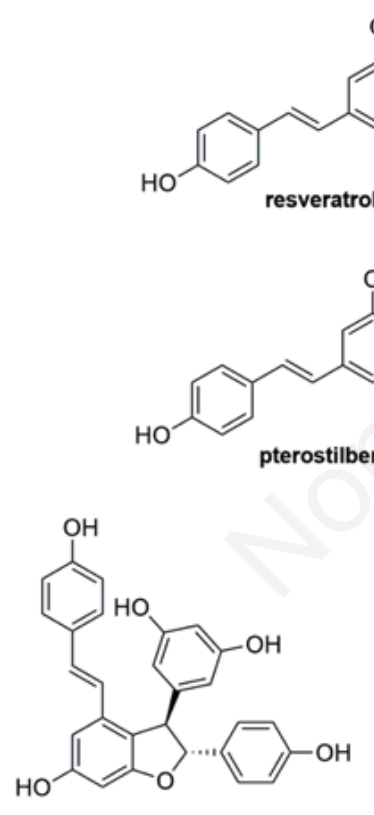

( \pm -trans- $\varepsilon$-viniferin<smiles>Oc1ccc(C2Oc3ccc(/C=C/c4cc(O)cc(O)c4)cc3C2c2ccc(O)cc2)cc1</smiles>

( \pm -trans- $\delta$-viniferin<smiles>Oc1cc(O)cc(C=Cc2ccc(O)c(O)c2)c1</smiles><smiles>COc1cc(/C=C/c2ccc(O)c(O)c2)cc(OC)c1</smiles><smiles>COc1cc(/C=C/c2ccc3c(c2)C(c2cc(OC)cc(OC)c2)OC3c2ccc(O)cc2)cc(OC)c1</smiles>

( \pm -pterostilbene-trans-dihydrodimer<smiles>Oc1ccc([C@H]2c3cc(O)cc(O)c3[C@H]3[C@@H](c4ccc(O)cc4)c4cc(O)cc(O)c4[C@H]23)cc1</smiles>

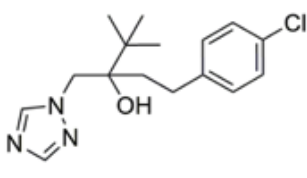

tebuconazole<smiles>Cc1cc(C2CCCCC2)n(O)c(=O)c1</smiles>

cyclopiroxolamine

Figure 1. Structure of selected stilbenoids, tebuconazole and cyclopiroxolamine. 
Table 1. Inhibitory activity of selected stilbenoids against filamentous fungi and yeasts.

\begin{tabular}{|c|c|c|c|c|c|}
\hline Fungi and yeasts & piceatannol & $\begin{array}{l}\text { 3'-hydroxy- } \\
\text { pterostilbene }\end{array}$ & $\begin{array}{l}( \pm) \text {-trans- } \delta \text { - } \\
\text { viniferin }\end{array}$ & $\begin{array}{l}( \pm) \text {-pterostilbene- } \\
\text { trans-dihydrodimer }\end{array}$ & pallidol \\
\hline Alternaria alternata & n.i. & n.i. & n.i. & n.i. & n.i. \\
\hline Aspergillus flavus & $20 \pm 0.0$ & $3 \pm 0.0$ & $5 \pm 0.2$ & n.i. & n.i. \\
\hline Aspergillus niger & n.i. & n.i. & n.i. & n.i. & n.i. \\
\hline Aspergillus ochraceus & n.i. & $5 \pm 0.1$ & n.i. & n.i. & n.i. \\
\hline Aspergillus terreus & $5 \pm 0.1$ & n.i. & n.i. & n.i. & n.i. \\
\hline Byssochlamys nivea & n.i. & n.i. & n.i. & n.i. & n.i. \\
\hline Botrytis cinerea & n.i. & n.i. & n.i. & n.i. & n.i. \\
\hline Fusarium graminearum & n.i. & n.i. & n.i. & n.i. & n.i. \\
\hline Fusarium verticillioides & $2 \pm 0.2$ & n.i. & n.i. & $10 \pm 0.0$ & $5 \pm 0.1$ \\
\hline Geotrichum candidum & $5 \pm 0.1$ & n.i. & n.i. & n.i. & n.i. \\
\hline Mucor circinelloides & n.i. & n.i. & n.i. & n.i. & n.i. \\
\hline Penicillium expansum & n.i. & n.i. & n.i. & n.i. & n.i. \\
\hline Penicillium italicum & n.i. & n.i. & n.i. & n.i. & $20 \pm 0.2$ \\
\hline Penicillium roqueforti & $20 \pm 0.1$ & $6 \pm 0.2$ & n.i. & n.i. & n.i. \\
\hline Rhizopus nigricans & n.i. & n.i. & n.i. & n.i. & n.i. \\
\hline Candida albicans & n.i. & $2 \pm 0.2$ & n.i. & n.i. & n.i. \\
\hline Candida parapsilosis & $2 \pm 0.0$ & $10 \pm 0.1$ & n.i. & n.i. & n.i. \\
\hline Malassetia pachydermatis & n.i. & n.i. & n.i. & n.i. & n.i. \\
\hline
\end{tabular}

molecule, although it is not possible to define a relationship between the structure of a given compound (number/position of $\mathrm{OH} /-\mathrm{OMe}$ groups) and its antimicrobial activity (Chalal et al., 2014). In general, the monomeric species (in particular piceatannol) were more active against the tested fungi compared to the dimeric derivatives. Interestingly, the tested stilbenoids were more active against phytopathogenic fungi (i.e., Aspergillus spp., Penicillium spp. and F. verticillioides). We can speculate that this behaviour could be related to the coevolution between pathogen and host plant (and its phytoalexins). In this sense, phytopathogenic fungi would be more sensitive to the fungitoxic effects of stilbenoids.

Interestingly, on dermatophyte fungi, inhibitory activity has been demonstrated at concentrations of $25-50 \mu \mathrm{g} / \mathrm{ml}$, while on Candida albicans it appeared evident at lower concentrations (10-20 $\mu \mathrm{g} / \mathrm{ml})$ (Vestergaard et al., 2019).

\section{Conclusions}

In this study, some stilbene derivatives were assayed and exhibited a weak to moderate antifungal activity against a panel of fungal strains and yeasts. Monomeric stilbenoids, in particular 3'-hydroxy-pterostilbene and piceatannol, and dimeric stilbenoids $( \pm)$-trans- $\delta$-viniferin and pallidol were active against mycotoxigenic fungi, thus showing a promising potential as food preservatives. In further studies, these compounds could be tested at higher concentrations, in combination with other natural compounds or low-dose conventional antimicrobials. In this view, stilbenoids could contribute to reduce the risk of selecting resistant fungal strains, a relevant issue due to the global burden of antimicrobial resistance. Finally, the efficacy of these compounds could be improved by formulation, including their functionalization with nanostructures or incorporation in active packaging.

\section{References}

Adrian M, Jeandet P, Veneau J, Weston LA, Bessis R, 1997. Biological activity of resveratrol, a stilbenic compound from grapevines, against Botrytis cinerea, the causal agent for gray mold. J Chem Ecol 23:1689-702.

Albert S, Horbach R, Deising HB, Siewert B, Csuk R, 2011. Synthesis and antimicrobial activity of (E) stilbene derivatives. Bioorg Med Chem 19:5155-66.

Bala AE, Kollmann A, Ducrot PH, Majira A, Kerhoas L, Delorme R, Einhorn J, 1999. Antifungal activity of resveratrol oligomers from Cyphostemma crotalarioides. Pestic Sci 55:206-8.

Caruso F, Mendoza L, Castro P, Cotoras M, Aguirre M, Matsuhiro B, Isaacs M,
Rossi M, Viglianti A, Antonioletti R, 2011. Antifungal Activity of Resveratrol against Botrytis cinerea is improved using 2-Furyl Derivatives. PLoS One 6:10.

Catalgol B, Batirel S, Taga Y, Ozer NK, 2012. Resveratrol: French paradox revisited. Front Pharmacol 3:141.

Chalal M, Klinguer A, Echairi A, Meunier $\mathrm{P}$, Vervandier-Fasseur D, Adrian M, 2014. Antimicrobial activity of resveratrol analogues. Molecules 19:7679-88.

Chan MMY, 2002. Antimicrobial effect of resveratrol on dermatophytes and bacterial pathogens of the skin. Biochem Pharmacol 63:99-104.

Chong J, Poutaraud A, Hugueney P, 2009. Metabolism and roles of stilbenes in plants. Plant Sci 177:143-55.

El Khawand T, Courtois A, Valls J, Richard T, Krisa S, 2018. A review of dietary stilbenes: sources and bioavailability. Phytochem Rev 17:1007-29.

Hoss G, Blaich R, 1990. Influence of Resveratrol on Germination of Conidia and Mycelial Growth of Botrytis cinerea and Phomopsis viticola. J Phytopathol 129:102-10.

Houillé B, Papon N, Boudesocque L, Bourdeaud E, Besseaù S, Courdavault V, Enguehard-Gueiffier C, Delanoue G, Guerin L, Bouchara JP, Clastre M, Giglioli-Guivarch N, Guillard J, Lanoue A, 2014. Antifungal Activity of Resveratrol Derivatives against Candida Species. J Nat Prod 77:1658- 
62.

Jaillon O, Aury JM, Noel B, Policriti A, Clepet C, 2007. French-Italian Public Consort. Grapevine Genome Charact. The grapevine genome sequence suggests ancestral hexaploidization in major angiosperm phyla. Nature 449:463-73.

Jeandet P, Delaunois B, Conreux A, Donnez D, Nuzzo V, Cordelier S, Clément C, Courot E, 2010. Biosynthesis, metabolism, molecular engineering, and biological functions of stilbene phytoalexins in plants. Biofactors 36:331-41.

Jeandet P, Vannozzi A, Sobarzo-Sanchez E, Uddin MdS, Bru R, Martinez-Marquez A, Clement C, Cordelier S, Manayi A, Nabavi SF, Rasekhian M, El-Saber Batiha G, Khan H, Morkunas I, Belwal T, Jiang J, Koffaso M, Nabavi SM, 2021. Phytostilbenes as agrochemicals: biosynthesis, bioactivity, metabolic engineering and biotechnology. Nat Prod Rep 1:1-48.

Lee J, Lee DG, 2015. Intracellular Mechanism of Resveratrol in C. albicans. Curr Microbiol 70:383-9.

Lee W, Lee DG, 2017. Resveratrol induces membrane and DNA disruption via prooxidant activity against Salmonella typhimurium. Biochem Biophys Res
Commun 489:228-34.

Ma DSL, Tan LTH, Chan KG, Yap WH, Pusparajah P, Chuah LH, Ming LC, Khan TM, Lee LH, Goh BH, 2018. Resveratrol - Potential Antibacterial Agent against Foodborne Pathogens. Front Pharmacol 9:102.

Oh WY, Shahidi F, 2018. Antioxidant activity of resveratrol ester derivatives in food and biological model systems. Food Chem 261:267-73.

Paul B, Chereyathmanjiyil A, Masih I, Chapuis L, Benoît A, 1998. Biological control of Botrytis cinerea causing grey mould disease of grapevine and elicitation of stilbene phytoalexin (resveratrol) by a soil bacterium. FEMS Microbiol Lett 165:65-70.

Sarig P, Zutkhi Y, Monjauze A, Lisker N, Ben-Arie R, 1997. Phytoalexin elicitation in grape berries and their susceptibility to Rhizopus stolonifera. Physiol Mol Plant Pathol 50:337-47.

Schouten A, Wagemakers L, Stefanato FL, Van der Kaaij RM, Van Kan JAL, 2002. Resveratrol acts as a natural profungicide and induces self-intoxication by a specific laccase. Mol Microbiol 43:883-94.

Seppanen VF, Vestergaard M, Ingmer H, 2019. Antibacterial and antifungal properties of resveratrol. Int $\mathrm{J}$ Antimicrob
Agents 53:716-23.

Shevelev AB, Isakova EP, Trubnikova EV, La Porta N, Martens S, Medvedeva OA, Trubnikov DV, Akbaev RM, Biryukova YK, Zylkova MV, Lebedeva AA, Smirnova MS, Deryabina YI, 2018. A study of antimicrobial activity of polyphenols derived from wood. Bull Russ State Med Univ 7:46-9.

Shevelev AB, La Porta N, Isakova EP, Martens S, Biryukova YK, Belous AS, Sivokhin DA, Trubnikova EV, Zylkova MV, Belyakova AV, Smirnova MS, Yulia I, Deryabina YI, 2020. In Vivo Antimicrobial and Wound-Healing Activity of Resveratrol, Dihydroquercetin and Dihydromyricetin against Staphylococcus aureus, Pseudomonas aeruginosa and Candida albicans. Pathogens 9:296.

Valletta A, Iozia LM, Leonelli F, 2021. Impact of Environmental Factors on Stilbene. Biosynthesis. Plants 10:90.

Vestergaard M, Ingmer H, 2019. Antibacterial and antifungal properties of resveratrol. Int $\mathrm{J}$ Antimicrob Agents 53:716-23.

Weber K, Schulz B, Ruhnke M, 2011. Resveratrol and its antifungal activity against Candida species. Mycoses 54:30-3. 